\title{
Dofequidar Fumarate
}

National Cancer Institute

\section{Source}

National Cancer Institute. Dofequidar Fumarate. NCI Thesaurus. Code C2231.

A synthetic quinoline derivative with multidrug resistance (MDR) modulating properties.

Dofequidar fumarate, like many other MDR reversal agents, binds competitively to the drug-binding site of the transmembrane P-glycoprotein efflux pump (P-gp). Once bound to the P-gp efflux pump, dofequidar is transported out of transformed cells by a mechanism similar to that used by cytotoxic drugs, thereby blocking the efflux of these compounds from the cell. Inhibition of the efflux pump by this agent leads to a retention of the cytotoxic drug resulting in increased intracellular drug concentrations, thereby enhancing cytotoxicity. Dofequidar has demonstrated reversal of the MDR phenotype in those cells exposed to various chemotherapeutic agents, such as vinca alkaloids and anthracyclines. 